\title{
Adult Neurogenesis Occurs in Primate Sensorimotor Cortex following Cervical Dorsal Rhizotomy
}

\author{
Mani Vessal and Corinna Darian-Smith \\ Department of Comparative Medicine, Stanford School of Medicine, Stanford, California 94305
}

\begin{abstract}
Adult neurogenesis remains controversial in the cerebral cortex. We have previously shown in monkeys and rats that reactive neurogenesis occurs in the spinal dorsal horn 6-8 weeks after a cervical dorsal rhizotomy. Here, in three monkeys with the same lesion, we asked whether it also occurs coincidentally in the corresponding primary somatosensory and motor cortex, where significant topographic and neuronal reorganization is known to occur. Monkeys (male Macaca fascicularis) were given 5-bromo-2-deoxyuridine (BrdU) injections 2-3 weeks after the rhizotomy, and were perfused 4-6 weeks later. Cells colabeled for BrdU and five different neuronal markers were observed within the primary somatosensory and motor cortex, and their distributions were compared bilaterally. Cells colabeled with $\mathrm{BrdU}$ and the astrocytic marker glial fibrillary acidic protein (GFAP) were also quantified for comparison. A significant number of $\mathrm{BrdU} / \mathrm{NeuN}$ - and BrdU/calbindin-colabeled cells were observed in topographically reorganized cortex. Small numbers of BrdU/GFAPcolabeled cells were also consistently observed bilaterally, but these cells were never colabeled with any of the neuronal markers. Of the cells colabeled with BrdU and a neuronal marker, at least half had an inhibitory phenotype. However, excitatory pyramidal neurons were also identified with classic pyramidal morphology. Cortical neurogenesis was not observed in other cortical regions. It was also not observed in the primary sensorimotor, prefrontal, or posterior parietal cortex in an additional control monkey (male Macaca fascicularis) that had no surgical intervention. Our findings provide evidence for reactive endogenous cortical neurogenesis after a dorsal rhizotomy, which may play a role in functional recovery.
\end{abstract}

\section{Introduction}

Neurogenesis is known to occur throughout adulthood in two neurogenic regions of the healthy forebrain, the dentate gyrus of the hippocampus, and the subventricular zone, which provides interneurons to the olfactory bulbs (Lledo et al., 2006). More recent reports that adult neurogenesis also occurs elsewhere in the brain, including the striatum, amygdala, and hypothalamus (Mitchell et al., 2004; Gould, 2007; Fowler et al., 2008) suggest that this phenomenon may be more widespread, but these findings require confirmation. Adult neurogenesis has also been reported in the normal rat (Kaplan, 1981; Dayer et al., 2005) and monkey cerebral cortex (Gould et al., 1999, 2001, 2007), though this finding remains somewhat controversial (Kornack and Rakic, 2001; Koketsu et al., 2003).

Adult neurogenesis is also induced in response to certain injury or disease states (Parent, 2002; Parent et al., 2002; Liu et al., 2009; Vandenbosch et al., 2009). For example, it has been observed after ischemia (Komitova et al., 2005; Hou et al., 2008; Ling et al., 2009; Liu et al., 2009), in multiple sclerosis (Danilov et al., 2006), and in mouse models of amyotrophic lateral sclerosis (ALS) (Chi et al., 2006). We have also recently shown reactive

\footnotetext{
Received 0ct. 23, 2009; revised April 5, 2010; accepted April 22, 2010.

This work was supported by the National Institute of Neurological Disorders and Stroke Grant R01 NS048425 (C.D.-S.). We thank Alayna Lilak for her technical assistance.

Correspondence should be addressed to Corinna Darian-Smith, Department of Comparative Medicine, Stanford School of Medicine, 300 Pasteur Drive, Edwards Building Room R350, Stanford, CA 94305-5342. E-mail: cdarian@stanford.edu.

DOI:10.1523/JNEUROSCI.5272-09.2010

Copyright $\odot 2010$ the authors $\quad 0270-6474 / 10 / 308613-11 \$ 15.00 / 0$
}

neurogenesis in rats and monkeys in the perilesion dorsal horn after a cervical dorsal rhizotomy (DRL) (Vessal et al., 2007), though neurogenesis has not been observed after central spinal injuries (Yang et al., 2006; Vessal et al., 2007). We previously proposed that this distinction between spinal root and central injuries is due, at least in part, to some of the many inhibitory factors produced by activated astrocytes associated with the extensive glial scarring that follows central injury.

What happens beyond the spinal cord at higher levels of the sensorimotor pathway where significant gliosis is thought to be absent? In the present study, we have begun to address this question by asking whether new endogenous neurons develop within the sensorimotor cortex in monkeys receiving a DRL. These were animals already known to exhibit neurogenesis within the cervical spinal cord (Vessal et al., 2007). We were specifically interested in looking within the region of cortical "hand" representation, which is known to reorganize topographically in direct response to the cervical DRL (Darian-Smith and Brown, 2000; Darian-Smith and Ciferri, 2006). Importantly, these animals were also known to recover function in the initially impaired digits of the affected hand, over the first 3-4 months after injury (Darian-Smith and Ciferri, 2005). In the present study, we examined the cortex of two of the same monkeys used in our previous investigation in the spinal cord (Vessal et al., 2007), as well as an additional animal, to address adult cortical neurogenesis after cervical spinal dorsal root transection. Our findings from these monkeys, plus an additional control monkey that did not receive a lesion, show that adult neurogenesis does occur within the somatosensory and motor cortex in direct response to a cervical dorsal root transec- 
tion. This indicates that responsive adult neurogenesis is not restricted to the site of injury, but is also induced at the higher cortical level several synapses away.

\section{Materials and Methods}

Four male colony-bred monkeys (Macaca fascicularis, M503, M504, M605, and M606, weighing 4.2, 3.8, 3.1, and $9.8 \mathrm{~kg}$, respectively) were used in this study and were housed in the Stanford Research Animal Facility in adapted 4-unit cages [each unit measuring (depth) $64 \times$ (width) $60 \times$ (height) $77 \mathrm{~cm}$ ]. The three experimentally lesioned monkeys (M503, M504, and M605) were young adults with half-grown canines, and were $>3.5$ years of age. The fourth monkey, M606 (9.8 kg and 10 years old), which did not undergo surgery, was used as a nonlesion control. All procedures were conducted in accordance with National Institutes of Health guidelines and approved by the Stanford University Institutional Animal Care and Use Committee.

Surgical procedures and making the dorsal rhizotomy. Monkeys M503, M504, and M605 underwent an initial laminectomy to produce a focal cervical dorsal rhizotomy that functionally deafferented the thumb, index, and middle fingers on one side. This procedure has been described previously (Darian-Smith and Brown, 2000; Darian-Smith and Ciferri, 2005, 2006; Vessal et al., 2007). Briefly, after an initial induction of anesthesia with ketamine hydrochloride $(10 \mathrm{mg} / \mathrm{kg})$, anesthesia was maintained with isoflurane $(1-1.5 \%) / \mathrm{O}_{2}$ throughout the aseptic surgery. Electrophysiological recordings were made within dorsal root fascicles spanning C5-C8 using standard tungsten microelectrodes (1-1.4 MW). This allowed us to create a microdermatome map of unitary responses ( $>10$ receptive fields per root fascicle) to cutaneous stimuli on the hand and to cut just those rootlets with detectable receptive fields on the thumb, index, and middle fingers of one hand. After making the lesion, the overlying fascia and skin were sutured in layers. Torbugesic $(0.02$ $\mathrm{mg} / \mathrm{kg}$ ) was given as the postoperative analgesic, and the monkey returned to its cage, where it was carefully observed. All monkeys recovered quickly without sequelae. See the articles cited above for further details of all aspects of the procedure and electrophysiological recording.

Two monkeys (M503 and M504) also underwent a second recovery surgery, during which they received a bilateral craniotomy to identify the region of cortical reorganization. After electrophysiological mapping of the cortical hand area, injections of anterograde tracers were made in the primary somatosensory and motor cortex, bilaterally, as part of a separate study. The tracers were injected via a glass micropipette $(<20 \mu \mathrm{m})$, at a depth of $1.2 \mathrm{~mm}$, and included Lucifer yellow dextran (15\%, Sigma), biotin dextran amine (15\%, Invitrogen), and tetramethylrhodamine dextran or FluoroRuby (FR) (10\%, Invitrogen). None of these tracers are associated with causing significant tissue damage/necrosis at the volume injected $(<0.4 \mu \mathrm{l} /$ injection $)$, and little damage was apparent histologically (i.e., in Nissl-stained sections) in subsequent serial reconstructions of the injection sites (see Fig. 1). To ensure that the injections themselves were not responsible for the changes observed in our study, a third animal was used (M605) that did not have a craniotomy.

5-Bromo-2-deoxyuridine administration and perfusion. Dividing cells were labeled using the thymidine analog 5-bromo-2-deoxyuridine (BrdU; Sigma). BrdU is incorporated into the DNA of the cell over $\sim 2 \mathrm{~h}$ from the time of injection (Cameron and McKay, 2001; Christie and Cameron, 2006). All monkeys were given two intravenous injections of $\mathrm{BrdU}(100 \mathrm{mg} / \mathrm{kg})$, with the first injection given as early as day 14 after surgery (M504) and the second injection as late as day 28 after surgery (M503). See the main text for details. Monkeys were killed 4 weeks after the last BrdU injection.

Before perfusion, monkeys were given ketamine $(10 \mathrm{mg} / \mathrm{kg})$ to induce anesthesia. A lethal intravenous dose of sodium pentobarbital $(0.44 \mathrm{ml} /$ $\mathrm{kg}$ ) was then administered, and on cessation of breathing and corneal reflex monkeys were perfused transcardially with physiological saline (1 $\mathrm{L})$ and $4 \%$ paraformaldehyde in $0.1 \mathrm{~m}$ phosphate buffer $\left(1.5 \mathrm{~L}, 4^{\circ} \mathrm{C}\right)$. The brain was removed, postfixed overnight, and cryoprotected in $20 \%$ sucrose. Tissue blocks were frozen and stored at $-80^{\circ} \mathrm{C}$.

Immunohistochemistry. The brain was blocked so that the primary somatosensory and motor cortex on either side of the central sulcus were contained in one block. All hemispheres but one in M503 were cut sagittally from lateral to medial, as indicated in the insets in Figure 5. Sections were cut ( $40 \mu \mathrm{m}$ thick) on a freezing microtome and stored free floating in $0.1 \mathrm{M}$ PBS $(0.9 \% \mathrm{NaCl}, \mathrm{pH} 7.4)$ for immunohistochemical processing. Sections to be immunoreacted for BrdU were initially denatured for $30 \mathrm{~min}$ in $2 \mathrm{M} \mathrm{HCl}$ in a $38^{\circ} \mathrm{C}$ water bath. They were then incubated in a $1 \mathrm{M}$ sodium borate solution, $\mathrm{pH} 8.5$, for $10 \mathrm{~min}$, washed in $0.1 \mathrm{~m}$ PBS, and blocked in goat serum (10\%; Invitrogen) for $2 \mathrm{~h}$. They were then incubated for $72 \mathrm{~h}\left(4^{\circ} \mathrm{C}\right)$ in a combination of anti-BrdU $(1: 100$; Accura Chemicals) and one of the following antibodies (for a detailed list, see Vessal et al., 2007). The neuronal precursor antibody Ki-67 (1:100; Vector Laboratories) was used in M503 and M605 in prefrontal and posterior parietal cortex in addition to BrdU/neuron-specific nuclear protein (NeuN), to identify newly formed cells. Neuronal antibodies used included the following: anti-NeuN, 1:200; monoclonal anticalbindin (CB) D-28 k, 1:5000; polyclonal anti-GABA, 1:200; and monoclonal anti-glutamic acid decarboxylase 67 (GAD67), 1:5000. Antibodies for mature astrocytes included the following: monoclonal anti-glial fibrillary acidic protein (GFAP), 1:500; and polyclonal anti-GFAP, 1:500. After incubating with the primary antibody, sections were washed in 0.1 M PBS, incubated with the appropriate fluorescent secondary antibody (2 $\mathrm{h}$ ), washed again, mounted onto slides, and coverslipped using the mounting medium (Gold antifade reagent, Invitrogen).

Histology. A series of sections (every 12th) were collected through the sensorimotor cortex bilaterally in each monkey and stained with $2 \%$ cresyl violet (Fig. 1). This allowed us to clarify areas according to their cytoarchitectonic characteristics and to determine the laminar distribution of identified newly formed neurons.

Controls. Two of the monkeys used in the present study (M503 and M504) were used in an earlier study (Vessal et al., 2007) that looked at adult neurogenesis in the spinal cords of monkeys after the DRL, and since the same antibodies were used in this study, the controls used in that work are relevant to the current study. These controls included the following.

First, colabeled cells within the somatosensory and motor cortex ipsilateral to the lesion were compared directly with labeling in cortex on the side contralateral to the DRL. This enabled a direct comparison to be made between the same functional regions on the two sides. Second, additional series of sections were collected for immunoprocessing from primary somatosensory and motor cortex distant to the region of hand and forearm representation. This allowed us to assess neurogenesis in cortex in the same monkeys that was not deprived of normal activation after the cervical DRL. An additional section series was also cut and processed within the prefrontal cortex to check for evidence of neurogenesis in this distant cortical region. Prefrontal cortical sections did have cells colabeled with BrdU and Ki67 (a marker for neural precursors), but no BrdU/NeuN-positive cells were identified. Sections distant to the deprived zone in primary sensorimotor cortex were also completely devoid of BrdU/NeuN-colabeled cells. Third, to further confirm the specificity of our labeling procedures in a well documented region of the brain, antibodies against BrdU, NeuN, and GFAP were tested in the dentate gyrus of the hippocampus, in the same monkeys, and in area CA3 in the rat. This is illustrated for monkey M503 as supporting material in our earlier article (Vessal et al., 2007), and in the control monkey M606 (see below) in the present study (supplemental Fig. 4, available at www. jneurosci.org as supplemental material). Hippocampal labeling matched all published accounts. Fourth, our earlier study shows the same antibody labeling specificity in rat spinal tissue. Finally, to eliminate autofluorescence or nonspecific binding, all tissue was incubated with secondary antibodies in the absence of primary antibody incubation.

In the present study, we also used an additional monkey that had no surgical procedures. We analyzed tissue sections for BrdU and NeuN through a $5.76 \mathrm{~mm}$ stretch of the primary sensorimotor cortex (including the region of hand representation), as well as a section series in both the prefrontal and posterior parietal cortex, and observed no colabeling of BrdU/NeuN in any of the regions examined. BrdU/NeuN colabeling was, however, observed in the dentate gyrus (supplemental Fig. 4, available at www.jneurosci.org as supplemental material). This provides ad- 


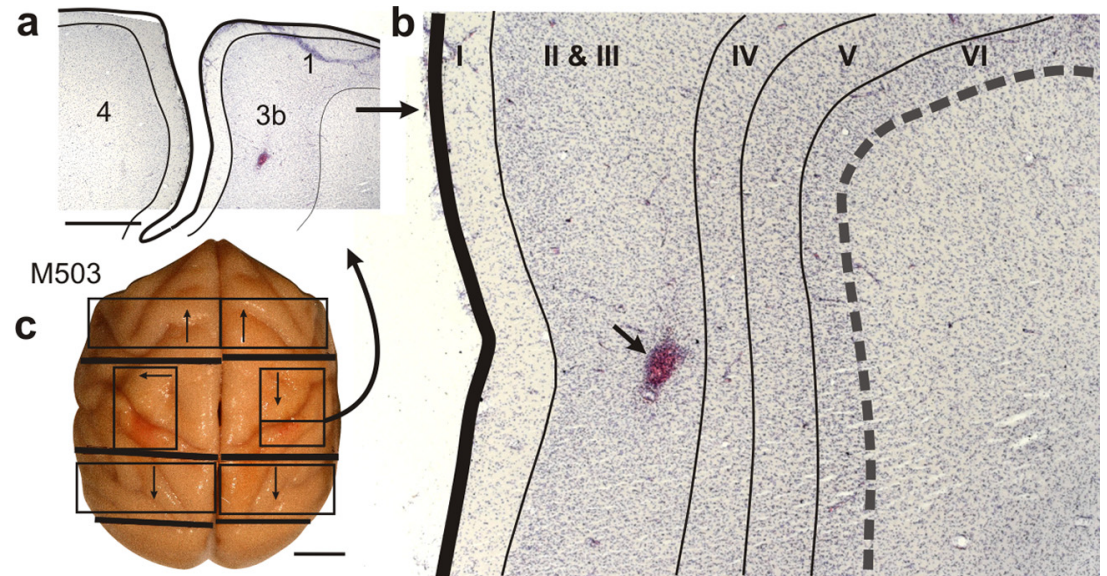

Figure 1. Histology of the somatosensory and motor cortex where neurogenesis was observed. Most cells were located in supragranular layers II and III, in the primary somatosensory cortex (areas 3b, 1, and 2). $\boldsymbol{a}, \boldsymbol{b}$, Section at the location indicated by the leading arrow in c. The injection site illustrates a FluoroRuby injection and shows the typical size and impact of these injections. Glial activity was confined to the immediate region of necrosis. These injections appeared to have little to no impact on the extent of adult neurogenesis observed in M503 and M504. c, The location of tissue blocks in M503, and thus the regions examined for neurogenesis in this monkey. Arrows inside each block boundary indicate the direction and plane of the section. Tissue sections were also examined within the prefrontal and posterior parietal cortical regions to determine whether neurogenesis occurred outside the region affected by the lesion. No neurogenesis was observed in these regions. Scale bars: $\boldsymbol{a}, 2 \mathrm{~mm} ; \boldsymbol{c}, 1 \mathrm{~cm}$.

ditional support that the neurogenesis observed in this study occurred as a direct result of the lesion.

Microscopy and quantification. Section series were analyzed using a Zeiss Pascal confocal laser-scanning microscope. All BrdU/NeuN, BrdU/ $\mathrm{CB}$, and BrdU/GFAP-colabeled cells were counted in sequential sections through the primary somatosensory and motor cortex. Counts were made using a fractionator sampling scheme modified from West et al. (1991). Colabeled astrocytes and neurons were counted as they came into focus while scanning through the $z$-axis of the sections. To eliminate bleed-through, secondary antibodies were selected with widely separated excitation and emission spectra, and different channels were collected sequentially with only one laser line on for each channel. When necessary, colabeling was confirmed by focusing through the BrdU-positive nucleus at higher magnification. The dissector height was set to $10 \mu \mathrm{m}$, and, to avoid oversampling, cells within the top and bottom $3 \mu \mathrm{m}$ of the section were not counted. The total number of labeled cells in the primary somatosensory and motor cortex was estimated using the equation, $N=\sum Q^{-} \times t / h \times 1 /$ asf $\times 1 / s s f$, where $\sum Q^{-}$was the total number of counted BrdU-, BrdU/NeuN-, BrdU/CB-, or BrdU/GFAP-labeled cells in the sensorimotor cortex, $t$ was the average section thickness, $h$ was the dissector height, asf was the area sampling fraction (equal to 1 as the entire cortical region was analyzed; this made fractionation of the sampling area in the $x-/ y$-axis unnecessary), and ssf was the section sampling fraction equal to $1 / 6$ or $1 / 12$ (where every 6 th or 12 th section was counted).

\section{Results}

\section{Procedural considerations}

Each of three monkeys (M503, M504, and M605) underwent a laminectomy, as has been previously described (Darian-Smith and Brown, 2000; Darian-Smith and Ciferri, 2005, 2006). Briefly, a partial microdermatome map was obtained using electrophysiological recordings within each of the dorsal rootlets receiving input from the digits of the hand. This has been illustrated for M503 in an earlier study (Darian-Smith and Brown, 2000; Vessal et al., 2007, Fig. 1). From the microdermatome map obtained for each monkey, just the rootlets carrying information from the first three digits of the dominant hand, were selected and cut. This translated to 2.5 cervical segments in each animal. The result was a focal cervical dorsal rhizotomy that functionally deafferented the thumb, index, and middle fingers (digits 1, 2, and 3) on one side. All three monkeys showed a severe initial deficit of digit function and substantial recovery in these digits over the first $6-8$ postlesion weeks. Though it was not possible to obtain behavioral data systematically (weekly) in the present study, the observations that were made directly corresponded with our earlier findings in animals with equivalent lesions (Darian-Smith and Ciferri, 2005). The assumption, based on our earlier work (Darian-Smith and Brown, 2000; Darian-Smith and Ciferri, 2005, 2006), was therefore made that there was corresponding cortical reorganization in the deprived somatosensory and motor cortex in these monkeys, and that this matched the functional recovery in their digits.

Two of the three lesioned monkeys in this study (M503 and M504) underwent a second recovery surgery, during which anterograde tracers [biotin dextran amine, Lucifer yellow dextran, and tetramethylrhodamine dextran (FR)] were injected (as part of another investigation) into the reorganized S1 hand cortex (Fig. 1). We were concerned that these injections might compromise our data by causing local changes to the extracellular environment that might induce or influence endogenous neurogenesis. To control for this, a third monkey (M605) was used, which was lesioned and treated exactly as the other two lesioned monkeys, but underwent no cortical procedures. Since our findings in all three monkeys were similar, it can be concluded that the tracer injections had little to no effect on the resulting cortical neurogenesis observed in M503 and M504. Quantitative data are therefore discussed below without reference to this procedural difference.

In monkeys M503 and M504, the tracer FR was transported retrogradely and anterogradely from injection sites into the primary somatosensory cortex in the digit 4-5 region. FR retrogradely labeled the cell body and proximal dendrites of neurons projecting to this region, so it effectively provided a fifth fluorescent marker for the $\mathrm{S} 1$ cortex in these two monkeys. In addition, neurons that were colabeled with BrdU/FR had known local projections to the adjacent cortex, which is known to receive input from digits 4 and 5 . These digits were not targeted but would have been partially deprived of their full complement of input after the dorsal root lesion. Importantly, this marker also provided morphological details not otherwise visible and made it possible to unequivocally identify some of the newly formed colabeled cells.

\section{Marker specificity}

A large number of controls were used in this investigation to ensure an accurate interpretation of our results (see Controls in Materials and Methods). Importantly, marker specificity was addressed directly for M503 and M504 in a previous study that examined adult neurogenesis in the spinal cord (Vessal et al., 2007). In that earlier study, tissue sections from the lesion and perilesion regions of the spinal cord were compared with spinal tissue taken rostral and caudal to the perilesion zone. In monkeys and rats that had received a DRL, no neurogenesis was observed outside the perilesion zone within the spinal cord (Vessal et al., 2007). Marker specificity was also checked by immunoprocessing tissue through the hippocampus in the same monkeys, in addi- 

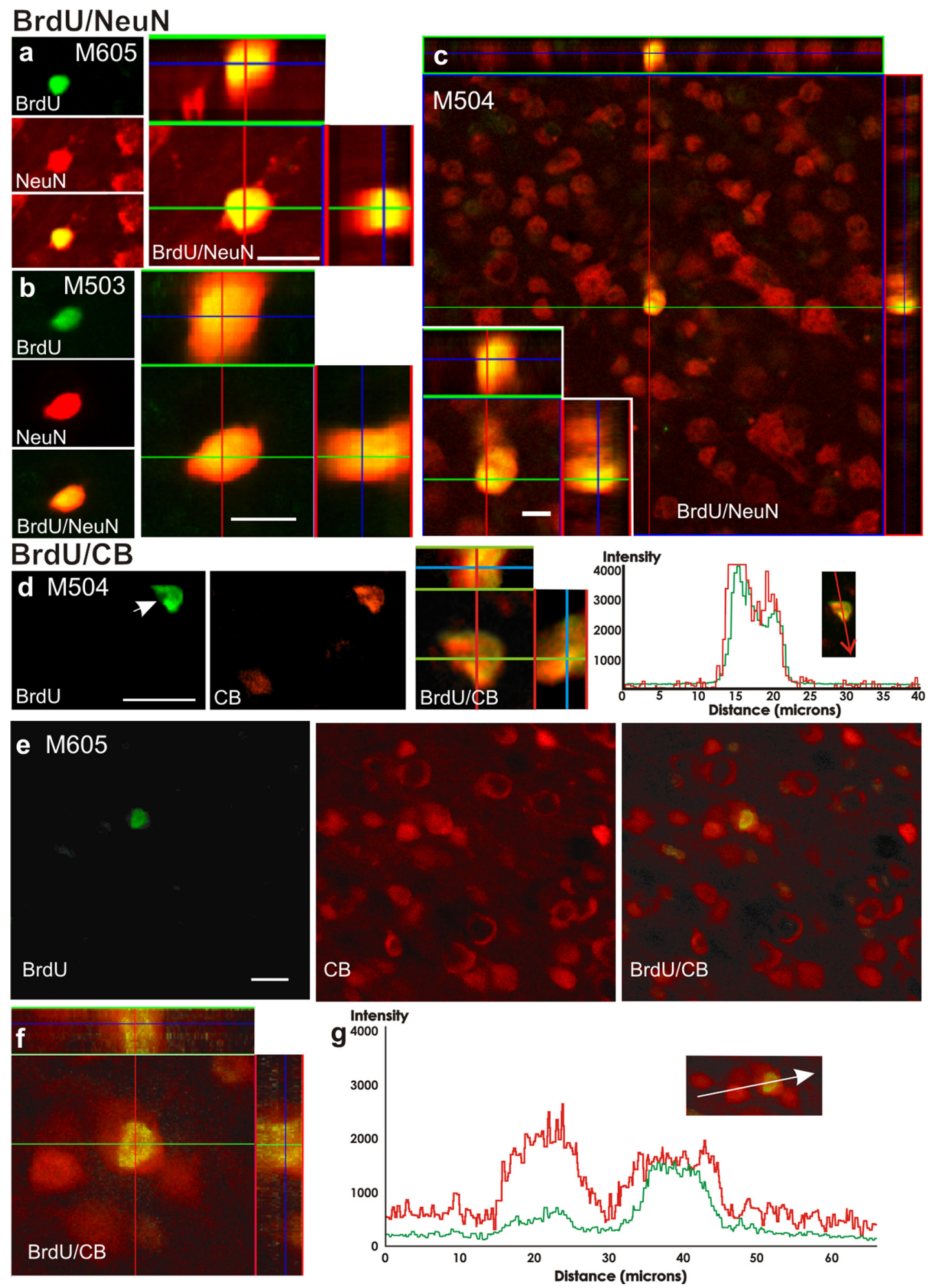

Figure 2. BrdU/NeuN- and BrdU/CB-colabeled cells were observed within the somatosensory and motor cortex (digit representation) contralateral to the side of the lesion. $\boldsymbol{a}-\boldsymbol{c}$, Confocal images of BrdU/NeuN-colabeled cells within somatosensory cortex, including orthogonal images created from z-series. Pia is located to right. $\boldsymbol{d}$, Confocal image of a BrdU/CB-colabeled neuron with a relatively small soma size, typical of these neurons. These cells were most likely inhibitory interneurons. An orthogonal image and spectral intensity profile of this colabeled cell provided additional confirmation of colocalization. See supplemental Figure 2 (available at www.jneurosci.org as supplemental material) for low-power images. $\boldsymbol{e}$, An additional example of a BrdU/CB-colabeled neuron from M605. Pia is located to the left of the image. $\boldsymbol{f}, \boldsymbol{g}$, An orthogonal image $(\boldsymbol{f})$ and spectral profile $(\boldsymbol{g})$ are given for this cell. Note the BrdU $-/ C B+$ cell also transected in the profile. Scale bars: $\boldsymbol{a}-\boldsymbol{d}, 10 \mu$ m; $\boldsymbol{e}, 20 \mu \mathrm{m}$. Cells illustrated in $\boldsymbol{a}-\boldsymbol{e}$ were located within deep layer 3 in Brodmann area $3 \mathrm{~b}$. 


\section{BrdU/GABA (M605)}
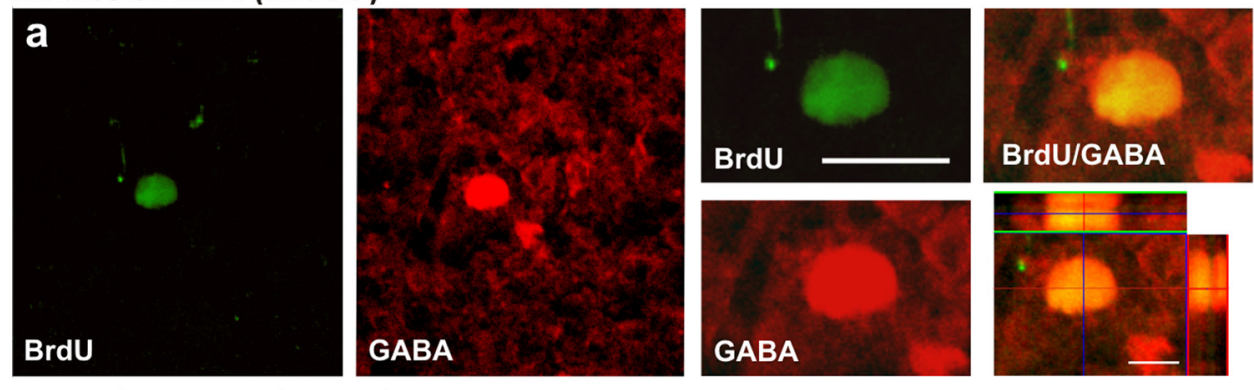

\section{BrdU/GAD67 (M605)}
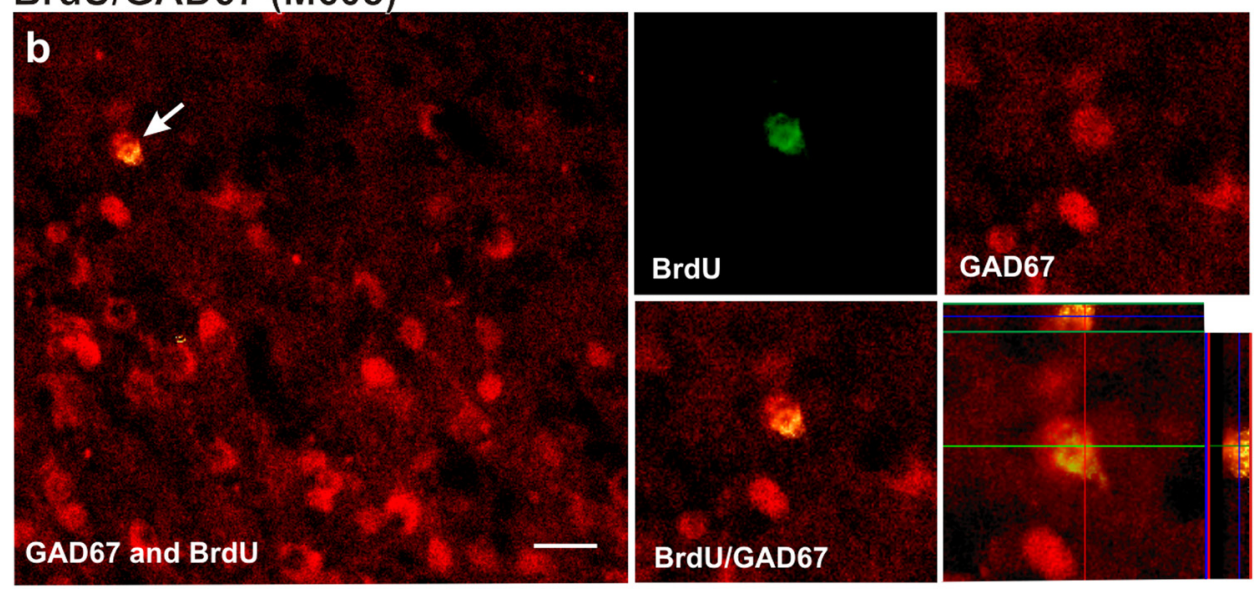

\section{BrdU and adjacent NeuN (M606)}
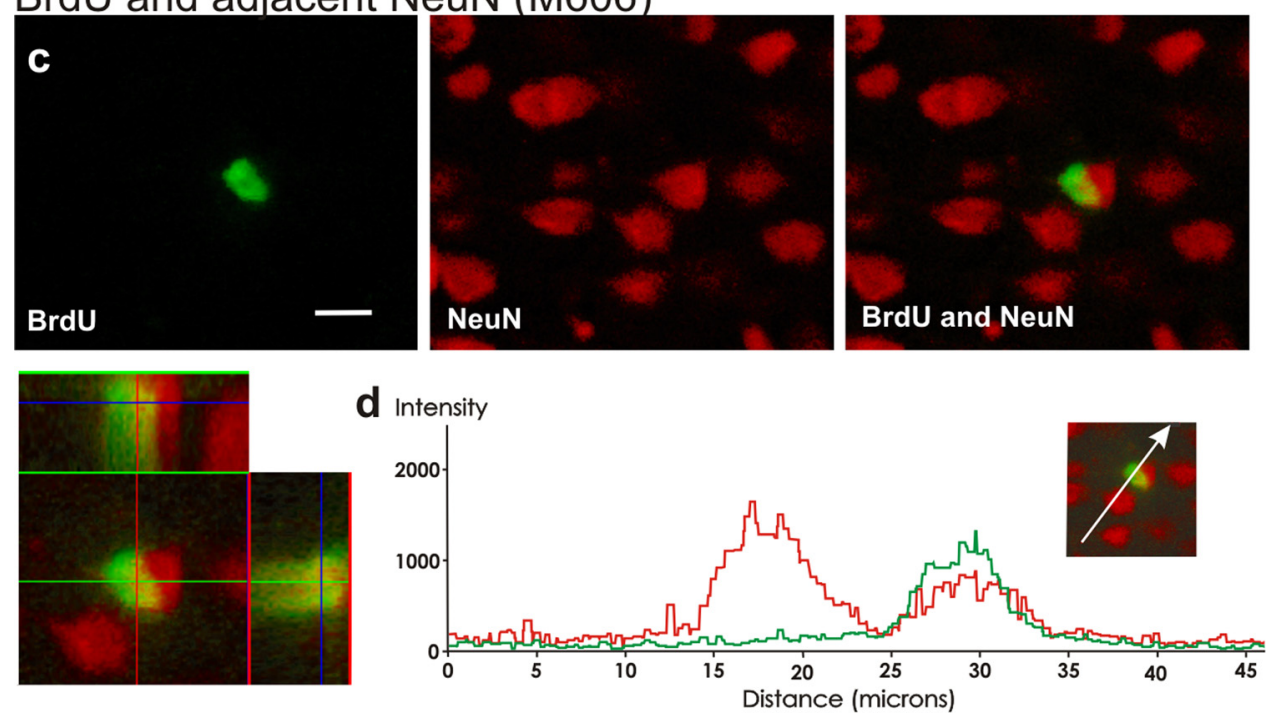

Figure 3. BrdU/GABA- and BrdU/GAD67-colabeled cells were also observed within the somatosensory and motor cortex contralateral to the side of the lesion. $\boldsymbol{a}$, Confocal image of a BrdU/GABAcolabeled neuron in somatosensory cortex at both low and higher power, with orthogonal view from z-series. There is a BrdU $-/ G A B A+$ cell close by. This cell was $\sim 12 \mu \mathrm{m}$ in diameter and located in layer 3 within cortical area $3 b$. $\boldsymbol{b}$, Confocal image of a BrdU/GAD67-colabeled neuron at low power (arrow) and higher magnification, with orthogonal image from $z$-series. Pia is to the left of image. c, Confocal image of a BrdU-labeled cell with an adjacent satellite NeuN-labeled neuron from the control monkey (M606) that did not receive a lesion. Pia is located to the left of the image. $\boldsymbol{d}$, A spectral profile showing that the BrdU-labeled cell overlays but lies outside the NeuN-labeled cell. Compare with colabeled cell spectral profiles in Figures $2 g$ and $4 f$. Scale bars: $\boldsymbol{a}-\boldsymbol{c}, 20 \mu \mathrm{m}$. All cells were located in deep layer 3 within Brodmann area $3 b$.

tion to looking at the hippocampus in the older control monkey M606 (supplemental Fig. 4, available at www.jneurosci.org as supplemental material), and the results matched published accounts. All antibodies used in the present study were also examined in lesioned and control rats in our earlier study (Vessal et al., 2007), again with results matching published accounts. In addition, in both monkeys and rats in the present and earlier study, none of the five antibodies used for mature neurons ever cola- beled cells expressing the astrocytic marker GFAP or the immature neuronal marker doublecortin (DCX).

Neurogenesis in reorganized sensorimotor cortex after dorsal rhizotomy

All monkeys received two injections ( $100 \mathrm{mg} / \mathrm{kg} /$ injection, i.v.) of the thymidine analog BrdU to visualize dividing cells (Figs. 2, 3, 4). M503 was injected on days 23 and 28 after the DRL, M504 on days 


\section{BrdU/NeuN colabeled pyramidal cells in somatosensory cortex}
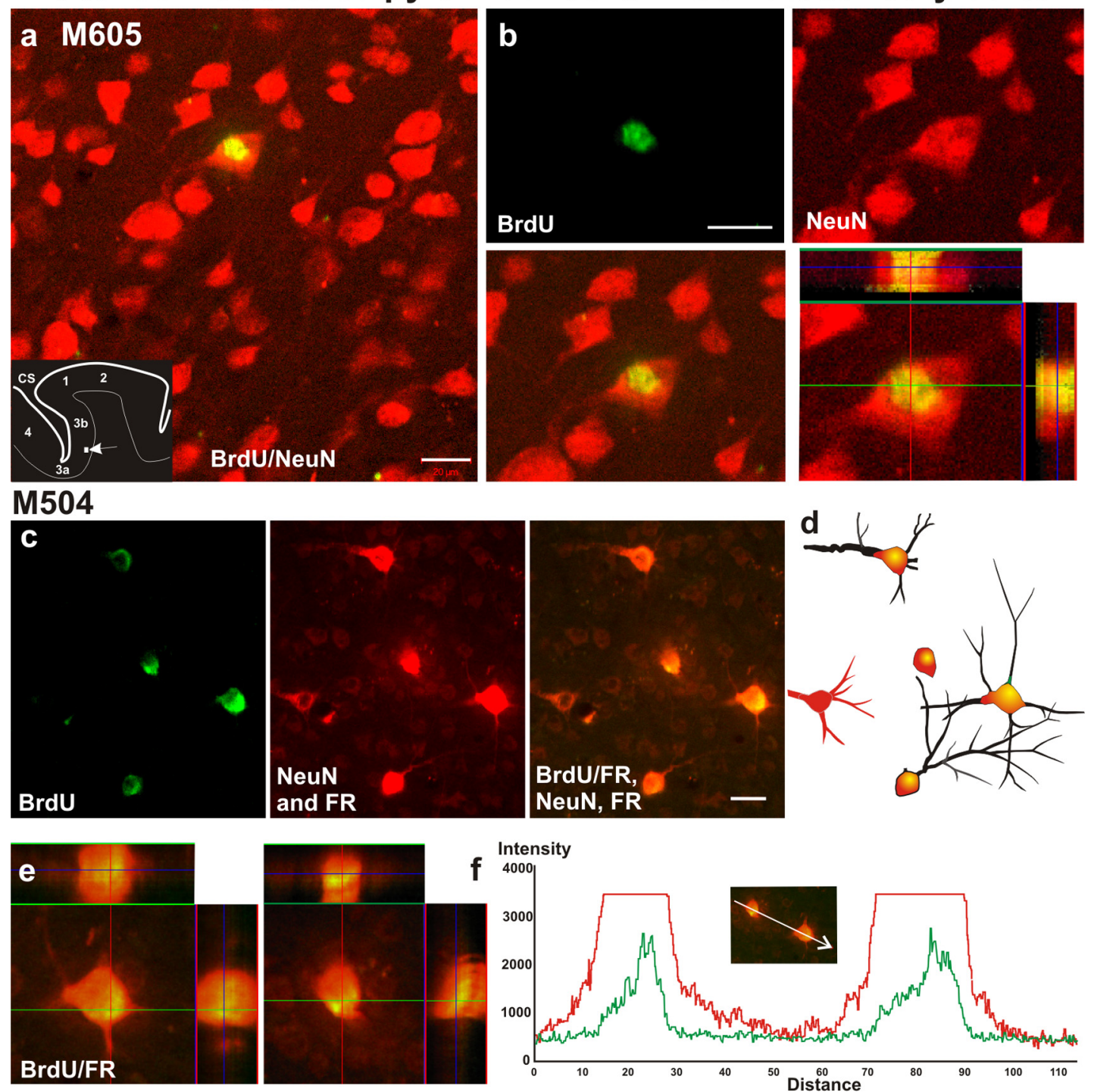

Figure 4. Newly formed neurons within the reorganized somatosensory cortex showing a pyramidal neuronal phenotype. $\boldsymbol{a}, \boldsymbol{b}$, Examples of BrdU/NeuN-colabeled neurons that had a pyramidal phenotype with respect to soma diameter and shape. Inset in a shows orientation and location of cells in layer V in Brodmann area 3b. See supplemental Figure 1 (available at www.jneurosci.org as supplemental material) for images from thez-plane gallery of the colabeled cell shown. $\mathbf{c}-\mathbf{f}$, Examples of BrdU/FR-colabeled neurons showing a classic pyramidal soma and dendritic morphology. Somata were $16-25 \mu \mathrm{m}$ in diameter and approximately twice the size of typical BrdU/CB-colabeled interneurons (see Fig. 3). $\boldsymbol{d}$, Reconstructions of BrdU/FR-colabeled neurons in c. Pia is to the left of image, and cells were located in deep layer 3 in area $3 b$. The red cell shown at the far left in c and $\boldsymbol{d}$ was FR positive but BrdU negative, and is an example of a mature neighboring pyramidal neuron. The absence of FR in the center of this cell is not atypical of an FR-labeled pyramidal neuron (for examples, see Bareyre et al., 2004; Schofield, 2008). Note that NeuN labeling appears faint in the image in crelative to the much brighter FR labeling. This reflects bright FR labeling and not faint NeuN labeling, and is a photographic artifact. Note that while both FR and NeuN were visualized at the same wavelength, the brighter FR labeling masked the fainter NeuN label, so only $\mathrm{BrdU} / F R$, and not BrdU/FR/NeuN, could be positively identified in the cells shown. NeuN does not label dendrites, which makes the identification of FR definitive. $\boldsymbol{e}$, Orthogonal view of colabeled cells in c and $\boldsymbol{d}$. $\boldsymbol{f}$, Spectral intensity overlays [for excitation wavelengths $488 \mathrm{~nm}$ (green) and $594 \mathrm{~nm}$ (red)] for two of the BrdU/FR-colabeled cells in cand $\boldsymbol{d}$. Scale bars: $\boldsymbol{a}-\boldsymbol{c}, 20 \mu \mathrm{m}$.

14 and 21, and M605 on days 22 and 23. Monkey M606, which had no surgical procedures, was injected in an identical manner, on 2 consecutive days. Monkeys were perfused $\sim 4$ weeks after their second BrdU injection (29 d for M503 and M504; $30 \mathrm{~d}$ for M605; and $34 \mathrm{~d}$ for M606).

Cells that had undergone mitotic division at the time of BrdU administration were BrdU positive, and cells that were BrdU positive that colabeled with NeuN, calbindin, GABA, or GAD67 were determined to be cells with a mature neuronal phenotype (Figs. 2, $3,4)$. Since injections of FR into somatosensory cortex (digits 4-5 representation) retrogradely labeled corticocortical pyramidal neurons within S1 cortex (i.e., Brodmann areas 3a, 3b, 1, and 2), FR also acted as a mature neuronal phenotypic marker in monkeys M503 and M504 (Fig. 4).
BrdU-, BrdU/NeuN-, and BrdU/CB-colabeled cells were counted in a series of sequential sections (taken every $480 \mu \mathrm{m}$ in M503 and M504, and every $240 \mu \mathrm{m}$ in M605) within the primary somatosensory and motor cortex (Fig. 5). Counts were made bilaterally in section series that passed through the regions of face, hand, and forearm representations. This included cortex (on the side contralateral to the lesion), which had reorganized topographically after the DRL (for a detailed description of topographic reorganization in this region, see Darian-Smith and Brown, 2000; and Darian-Smith and Ciferri, 2006). Though the side ipsilateral to the lesion was not directly affected by the DRL, callosal projections are known to link regions of hand representation in the two hemispheres, and callosal activation to the area from the first three digits was partially blocked after the injury. 
Thus, while we refer to the ipsilateral cortex as the normal or control side, it should be noted that the lesion had some effect, albeit subtle, on this hemisphere (Figs. 5, 6).

To ensure that the subtle proliferation observed within the ipsilateral primary sensorimotor cortex was due to the DRL and was not simply baseline proliferation, we also used a control monkey that did not undergo any surgical procedure (M606). No BrdU/NeuN colabeling was observed in the primary sensorimotor, prefrontal, or posterior parietal regions examined in this control. This adds additional support that the neuronal proliferation observed in the three lesioned monkeys had occurred in direct response to the DRL.

Distribution profiles were plotted through the primary sensorimotor cortex in all animals as illustrated in Figure $5 A-C$. As is evident in these profiles, the numbers of BrdU-, BrdU/NeuN-, and BrdU/CB-colabeled cells were far greater in cortex contralateral to the lesion, compared with the ipsilateral side. When total numbers were calculated for each hemisphere using confocal microscopy and the fractionator method (West et al., 1991), and the data from the two sides compared statistically (using a paired sample $t$ test), the difference between the hemispheres was found to be significant $(p<0.001)$ (Fig. 6). In all three lesioned monkeys, the number of cells colabeled with BrdU/NeuN and BrdU/CB, which indicated newly born neurons, peaked in the reorganized cortex, in the region of hand representation, and dropped gradually to negligible levels on either side of this region. Interestingly, neurogenesis extended several millimeters beyond the region of digits 1-3 representation (Fig. 5C, insert, where hand representation is indicated). This may reflect the full extent of thalamocortical input into this region of the cortex, which can diverge over 2-3 mm (Darian-Smith and Darian-Smith, 1993; Rausell et al., 1998; Darian-Smith et al., 1999). Very few BrdU-labeled, or BrdU/NeuN- and BrdU/CBcolabeled cells were observed in the equivalent location in the contralateral cortex (Figs. 5, 6a).

\section{Neurogenesis in sensorimotor cortex beyond the region of peripheral deprivation}

Additional section series were cut several millimeters medial and lateral to those included in the distribution profiles shown in Figure 5 to check for evidence of newly born neurons in supposedly normal primary somatosensory and motor cortex. Given that the numbers of colabeled neurons were very small in the ipsilateral cortex (Fig. $6 c$, estimated total numbers of labeled cells), these sections were only collected for immunoprocessing on the side contralateral to the lesion. We observed no BrdU/ $\mathrm{NeuN}$ - or BrdU/CB-colabeled cells in any of the sections analyzed distant to the reorganized region (where $n=12$ sections/ monkey, or 6 sections separated by $480 \mu \mathrm{m}$ in cortex located medial and lateral to the region of hand and forearm representation). All three lesioned monkeys were analyzed in this way in sensorimotor cortex. These data were consistent with our observations in the nonlesioned control monkey (M606), where no BrdU/NeuN colabeling was observed at all in the primary sensorimotor cortex, and point to a causal relationship between the cervical DRL and the proliferation observed in reorganized primary sensorimotor cortex.

To determine whether neurons were formed in similar or dissimilar proportions on the two sides of the cortex, calculated totals (see description of the fractionator analysis in Materials and Methods) were used to determine the percentage of all newly born BrdU-labeled cells that were neurons, activated astrocytes, or cells of unknown phenotype (e.g., microglia, oligodendrocytes, and neuroepithelial cells). As shown in Figure $6 b$, on the side contralateral to the lesion, $34 \pm 12 \%$ of all BrdU-labeled cells were neurons and $55 \pm 8 \%$ were of unknown non-neuronal phenotype (e.g., astrocytes, microglia, and oligodendrocytes). This ratio was greater in M605 on the side ipsilateral to the lesion, but was similar on the two sides in M503 and M504. Though additional data are needed, our data suggest a similar proportion of newly formed cells in both hemispheres.

The vast majority of the newly formed neurons observed were distributed in the primary somatosensory rather than the motor cortex, and this is evident in the distribution profiles shown in Figure 5. This is not surprising, since almost all of the ascending sensory input blocked after the DRL projects to the primary somatosensory cortex. Within the somatosensory cortex, most colabeled neurons $(>80 \%)$ were located in the superficial laminae $2-3$, though this distribution was not exclusive of the deeper layers.

\section{Newly born neurons have a heterogeneous morphology}

The retrograde labeling of pyramidal neurons in S1 in M503 and M504 (resulting from FR injections) enabled us to visualize and reconstruct (using $z$-series confocal images) the dendrites of these neurons (BrdU/FR-colabeled cells) within the somatosensory cortex (Fig. $4 c, d$ ). Since they were labeled from injection sites several millimeters away, these cells had axons extending at least $3 \mathrm{~mm}$. Though it was not possible to reconstruct entire cells, it was possible to reconstruct partial or complete dendrites in a number of these colabeled neurons. Several examples of FRlabeled pyramidal neurons without BrdU were also reconstructed for direct comparison (Fig. $4 c$, see example). In contrast to previous reports of neurogenesis in the cortex and elsewhere (Dayer et al., 2005; Cameron and Dayer, 2008), our reconstructions showed cell body diameters ranging between 16 and $25 \mu \mathrm{m}$, and a dendritic structure typical of pyramidal neurons in the same vicinity (Fig. $4 c, d)$, complete with apical and basal dendritic branches. BrdU/CBcolabeled neurons were consistently much smaller, as is typical of inhibitory interneurons and had soma diameters that were 6-10 $\mu \mathrm{m}$. FR/CB- and FR/GAD67 (with or without BrdU)-colabeled cells were never observed, which further supports an excitatory, rather than an inhibitory, phenotype in this subpopulation of newly formed BrdU/FR-colabeled neurons.

Our data show that $\sim 55 \pm 16 \%$ of the newly formed neurons were $\mathrm{CB}$ positive (Figs. 5,6$)[(\mathrm{BrdU} / \mathrm{CB}) /(\mathrm{BrdU} / \mathrm{NeuN})]$, and the majority of the remaining BrdU/NeuN neurons were also likely to be inhibitory (judging by their smaller cell soma diameters). Nonetheless, our findings also show that at least a small percentage was excitatory pyramidal neurons (presumably glutamatergic).

\section{Astrocytic activation in the reorganized cortex}

Since astrocytic activation plays such a large role in the changes that take place at and around a CNS injury site (Silver and Miller, 2004; Feeney and Stys, 2005; Rolls et al., 2009), we asked whether astrocytic activation also potentially plays a role in the cortical neurogenesis observed in this study. To look at this, we counted cells that were colabeled with BrdU and the astrocytic marker GFAP, as we had done in our earlier study in the spinal dorsal horn (Vessal et al., 2007). As shown in Figures 5 and 6, we did find BrdU/GFAP-colabeled cells within the sensorimotor cortex. Total numbers were small overall, but there were significantly more $(p<0.01)$ (Figs. 5, 6) proliferating astrocytes in the affected primary sensory and motor cortex after the DRL, compared with the ipsilateral side. The smallest numbers were observed in monkey M605, which had the greatest amount of neurogenesis. However, a potential link between these two variables is only suggestive at this stage. 
Reactive neurogenesis in primary sensorimotor cortex
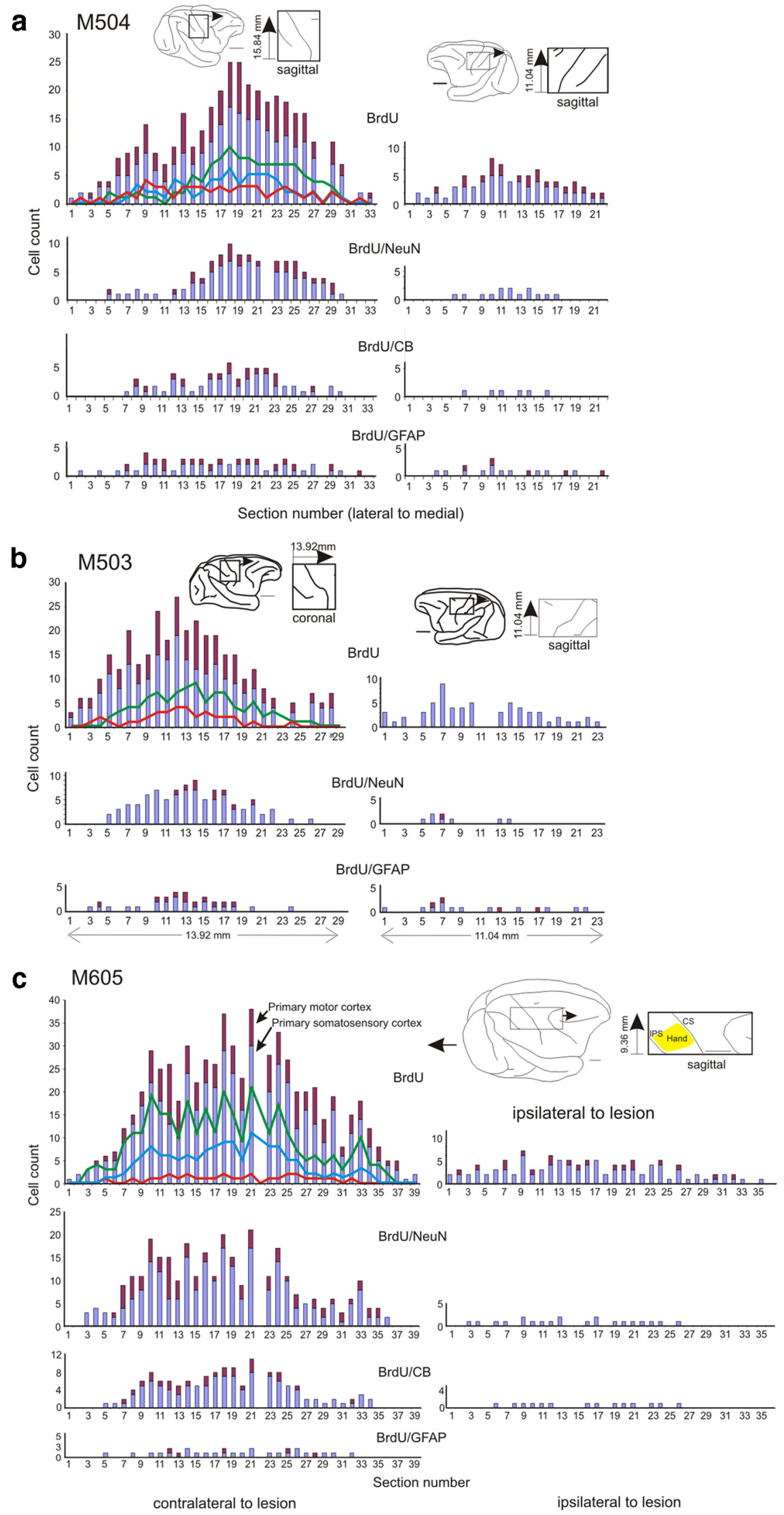

Figure 5. Neurogenesis was consistently observed at significant levels in the sensorimotor cortex contralateral to the dorsal root lesion (in the region of hand and forelimb representation). $\boldsymbol{a}-\boldsymbol{c}$, Distribution profiles for BrdU-labeled, and for BrdU/NeuN-, $\mathrm{BrdU} / \mathrm{CB}-$, and BrdU/GFAP-colabeled cells in each monkey. BrdU was consistently elevated on the side contralateral to the lesion

\section{Neurogenesis within prefrontal and posterior parietal cortex}

To see whether there was evidence of neurogenesis in cortical regions well removed from the perilesion regions, we also examined two regions outside the primary sensorimotor cortex. Section series (every 12 sections or $480 \mu \mathrm{m}$ ) were collected in two lesioned monkeys (M503 and M605) through (1) the prefrontal cortex, (2) the posterior parietal cortex, and (3) from somatosensory and motor cortex in regions receiving input from the face (more laterally) and the hindlimb or tail (more medially). Section series were also collected in the control monkey from prefrontal, posterior parietal, and the primary sensorimotor cortex. Adjacent section series through each of these regions (24 sections spanning $11.52 \mathrm{~mm}$ of tissue in each region in monkeys M503 and M605) were immunoreacted to visualize $\mathrm{BrdU} / \mathrm{Ki} 67$ and BrdU/NeuN. In the nonlesioned control monkey M606, 12 sections spanning $5.76 \mathrm{~mm}$ in the sensorimotor cortex, and 4 sections spanning $1.44 \mathrm{~mm}$ in the prefrontal and posterior parietal cortex were also immunolabeled with BrdU and NeuN. Excellent labeling was observed for each of these antibodies. BrdU/Ki67 colabeling was observed consistently within prefrontal and posterior parietal sections in small numbers (range: $3-6$ cells/section in posterior parietal; $1-3$ cells/section in prefrontal). However, BrdU and NeuN colabeling was not observed in any of the sections examined within the prefrontal cortex, posterior parietal cortex, or sensorimotor cortex in regions outside the input deprived zone (in M503 and M605), at the 6-8-week time point after the lesion (i.e., 4 weeks after BrdU injection). In addition, no BrdU/NeuN colabeling was observed in any cortical region examined in the nonlesioned control monkey.

(left) compared with the same region on the ipsilateral side (right), and with all other regions of cortex outside the hand/ arm representation (not illustrated; but no BrdU/NeuNcolabeled cells were observed anywhere else in the cortex; see text). Within graphs: red, cells counted in motor cortex; blue, cells counted in somatosensory cortex. Lines drawn over the BrdU profiles trace the BrdU/NeuN (green line), BrdU/CB (blue line), and BrdU/GFAP (red) distribution profiles (shown in the graphs) so that these populations can be compared directly with overall BrdU proliferation. Insets show the exact regions of analysis and the orientation and direction of section series. Tissue section numbers are shown on the $x$ abscissa, and the cell counts for individual sections are plotted. The region of hand representation is indicated in c for M605. 


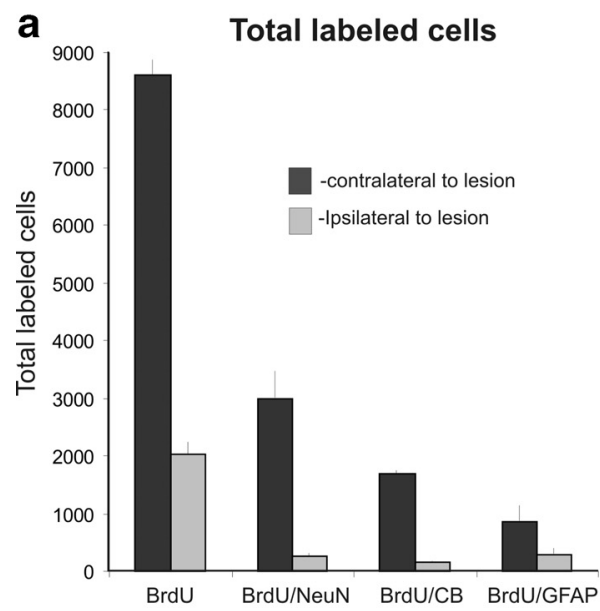

\section{b Percentage of total BrdU} -contralateral to lesion

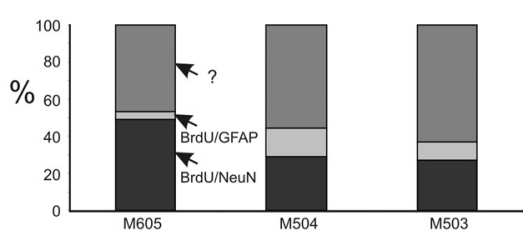

-Ipsilateral to lesion

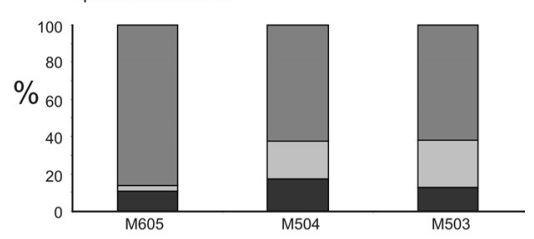

Total labeled cells per animal

\begin{tabular}{|c|c|c|c|c|c|c|c|c|}
\hline & \multicolumn{7}{|c|}{ Total labeled cells per animal } & \\
\hline & \multicolumn{2}{|c|}{ BrdU } & & & \multicolumn{2}{|c|}{$\mathrm{BrdU} / \mathrm{CB}$} & \multicolumn{2}{|c|}{ BrdU/GFAP } \\
\hline & contra & ipsi & contra & ipsi & contra & ipsi & contra & ipsi \\
\hline M605 & 8150 & 2488 & 4000 & 263 & 1750 & 175 & 363 & 75 \\
\hline M504 & 9175 & 2000 & 2675 & 350 & 1625 & 150 & 1425 & 400 \\
\hline M503 & 8475 & 1575 & 2325 & 200 & & & 825 & 400 \\
\hline
\end{tabular}

Figure 6. A comparison of labeling in somatosensory and motor cortex in hemispheres contralateral and ipsilateral to the dorsal root lesion. $\boldsymbol{a}$, Graph comparing total numbers of labeled cells in the two hemispheres calculated using the fractionator method (West et al., 1991). $\boldsymbol{b}$, Graph showing the proportion (expressed as a percentage) of BrdU-labeled cells that were neurons, astrocytes, and of an unidentified phenotype (?). Note that proportions were not dissimilar within the two hemispheres in two of the monkeys, despite a very large difference in the total numbers present on the two sides, shown in $\boldsymbol{a}$. More than $50 \%$ of all BrdU-labeled cells were unidentified within the contralateral cortex (e.g., microglia, oligodendrocytes, and neuroepithelial). c, Total estimated numbers of cells within the contralateral and ipsilateral somatosensory and motor cortex in each of the three experimentally lesioned monkeys. Note that totals grossly underestimate actual totals, since they refer only to those cells that took up BrdU at the time of BrdU injection (and for $\sim 2 \mathrm{~h}$ after BrdU injection).

\section{Discussion}

Our results present the first evidence that adult neurogenesis occurs in the nonhuman primate primary somatosensory and motor cortex in direct response to a spinal dorsal root injury. Importantly, we provide strong evidence that new neurons were formed within reorganized but uninjured cortex in response to a cervical deafferentation occurring many synapses from the site of injury or any significant gliosis associated with the injury.

Reactive adult cortical neurogenesis has been demonstrated previously in rodent models of ischemia (Parent, 2002; Kokaia et al., 2006; Thored et al., 2006; Ling et al., 2009), multiple sclerosis (Danilov et al., 2006), ALS (Chi et al., 2006), epilepsy (Scott et al., 1998; Parent, 2002; Jessberger and Parent, 2008), and after focal apoptosis (Magavi et al., 2000). This study now shows that a spinal dorsal rhizotomy can also induce endogenous neurogenesis within the nonhuman primate cortex. Since we recently also observed neurogenesis within the deprived cervical spinal dorsal horn (Vessal et al., 2007), it can be concluded that reactive neurogenesis occurs at multiple levels of the somatic sensorimotor pathway in direct response to a dorsal rhizotomy.

The great majority of newly formed neurons $(\sim 80 \%)$ were located in the somatosensory cortex after the DRL, within the region most directly deprived of normal hand input. A smaller number were observed in the primary motor cortex, but this is not surprising given that somatosensory input to monkey motor cortex (Evarts and Fromm, 1977; Strick and Preston, 1978; Tanji and Wise, 1981) is very small. What was surprising was that the cortical neuronal proliferation was so distant to the deafferenta- tion, and that newly formed neurons were also observed in the corresponding ipsilateral cortex. This suggests an exquisitely sensitive system, in which the disruption of activity along primary afferent and callosal projections (caused by a focused DRL) is sufficient to induce neurogenesis and glial activation within both cortical hemispheres.

Calbindin-labeled neurons comprised a little over half of the newly formed neuronal population observed within the sensorimotor cortex in our animals. Given this, and the small cell soma size of most of the BrdU/NeuN-colabeled neurons, it can be concluded that the majority were phenotypically inhibitory, which fits with previous reports of cortical (Gould et al., 1999; Gould, 2007) and spinal (Vessal et al., 2007) neurogenesis. That a small population of the newly formed neurons were morphologically pyramidal is, however, a novel finding and indicates a more heterogeneous population of cortical neurons being formed than has been previously reported (Cameron and Dayer, 2008). Newly formed pyramidal neurons have been reported in mouse cortex in a model of targeted cell death (Magavi et al., 2000), but the relationship between these findings and our own is unclear. The DRL in the current study was unlikely to cause transsynaptic cortical apoptosis several synapses away in the time frame examined. Since the pyramidal neurons in this study were labeled from a neuronal tracer injected 3-5 mm away, these cells were corticocortical with short-range connections to neighboring regions of the $\mathrm{S} 1$ hand cortex (i.e., regions less affected by the lesion). Pyramidal neurons were observed mainly but not exclusively in the infragranular cortical layers, which also matches known accounts of corticocortical neuronal populations in the somatosensory cortex of primates (Wu and Kaas, 2003). These pyramidal neurons were also mature morphologically, which suggests they may already be integrated and functional within the local cortical circuitry, but further evidence is needed to clarify this and to determine the longevity of these cells. Recent studies in the hippocampus and elsewhere provide evidence that newly formed neurons in the adult CNS can integrate and function appropriately within local circuitry (Ge et al., 2008; Imayoshi et al., 2008). Though it is not currently known, the cortical neurogenesis observed in the present study may be acting to remodel, replace, or supplement neuronal circuits within the partially deprived cortex.

\section{Technical considerations}

In the present study, we did not observe adult neurogenesis outside the region of cortex deprived of normal activation from the hand after the DRL. This is in keeping with our observations in the spinal cords in the same monkeys (Vessal et al., 2007), where neurogenesis was observed in the perilesion region of the cervical cord but not in cord distant to the site of the lesion. In addition, we did not observe BrdU/NeuN or BrdU/CB colabeling in any region of cortex in the control monkey (M606), which had no 
surgery. Since neurogenesis was only observed within "reorganized" cortex in the lesioned animals in this study, and the perilesion spinal cord in our earlier report (Vessal et al., 2007), there is clearly a causal relationship between the neurogenesis and the lesion. What exactly causes or enables the induction of neurogenesis in the cortex after a dorsal root deafferentation is not known. The cessation of normal activity within the cortex appears to play a critical part, but little else is clear. The reason for astrocytic proliferation within the region of cortical neurogenesis is also unclear, though these cells may play a permissive or supportive role at low levels (Jiao and Chen, 2008).

It is unlikely that the labeled neurons observed in the present study were apoptotic or even nonapoptotic cells undergoing de novo DNA repair, though this possibility cannot be completely dismissed (Burns et al., 2007). Evidence against this comes from earlier work from our laboratory (Vessal et al., 2007) and others (Bauer and Patterson, 2005; Gould, 2007; Taupin, 2007), and from the present investigation. As part of our spinal cord study (Vessal et al., 2007), which used two monkeys from the present study, the colabeling of BrdU and an immature (DCX) and a mature neuronal marker (NeuN) was assessed in the spinal cord at two survival time points ( $24 \mathrm{~h}$ and 3-4 weeks) after BrdU injection. At the $24 \mathrm{~h}$ time point, BrdU/DCX but no BrdU/NeuN colabeling was observed, whereas at 3-4 weeks we observed BrdU/NeuN-colabeled cells but no BrdU/DCX colabeling. If our colabeled cells were mature neurons that took up BrdU as a result of undergoing de novo DNA repair, apoptosis, or some other process characteristic of postinjury damage, we would have anticipated BrdU/NeuN colabeling at the $24 \mathrm{~h}$ stage. However, this was never observed. Though pertinent to the present study, these findings did not directly address cortex. To test this, we examined cortical tissue in one of the monkeys (M507) from our previous study, which had been injected with BrdU 18 and $19 \mathrm{~d}$ post-DRL and perfused $24 \mathrm{~h}$ later. In a series of 12 sections ( $40 \mu \mathrm{m}$, sampled every $150 \mu \mathrm{m})$, taken through reorganized sensorimotor cortex, we observed BrdU- and NeuN-labeled cells but no BrdU/NeuNcolabeled cells. Our data from both cord and cortex support the interpretation that neuronal progenitors in the cortex developed to a mature phenotype and were not undergoing DNA repair.

Since the experimental animals used in the present study were young adults just reaching sexual maturity, future studies will be needed to confirm that the injury-induced neurogenesis we observe in the primary sensorimotor cortex (hand region) occurs as vigorously in significantly older animals. Previous work in older monkeys in the hippocampus shows a decreased rate of neurogenesis in much older animals (Leuner et al., 2007), but not an absence of it, so we might hypothesize a less vigorous injuryinduced response, but a continued response nonetheless. At present, this is not known. In the present study, data from the 10 -year-old control monkey confirmed what we observed in the younger adults. That is, we found no colabeling of markers suggesting neurogenesis either in the nondeprived sensorimotor cortex or elsewhere in the cortex (i.e., prefrontal and posterior parietal cortex).

\section{Neurogenesis in other cortical regions}

Though this was not the primary focus of the study, cortical regions outside the primary sensorimotor "hand and forelimb" areas, including prefrontal and posterior parietal cortical regions, were also examined for evidence of neurogenesis. Earlier reports of neurogenesis have been made in these cortical regions in the "normal" but environmentally enriched monkey (Dayer et al., 2005; Gould et al., 1999, 2001; Bernier et al., 2002; Gould, 2007), but such reports have not been repeated in the primate (Kornack and Rakic, 2001; Koketsu et al., 2003; Gould, 2007). We were therefore interested in assessing adult primate cortical neurogenesis in this study, outside the sensorimotor hand region most directly deprived of normal input after the lesion. Prefrontal and posterior parietal cortex, as well as nondeprived somatosensory and motor cortex (i.e., face and tail regions in lesioned animals, and the forelimb and hand regions in the control monkey) were therefore examined in two lesioned monkeys and the control monkey. We found no evidence of neurogenesis in any of the nondeprived cortical regions in any of these monkeys, at the 6-8-week time point after the lesion (i.e., 4 weeks after BrdU injection). Though only three monkeys were examined, the findings were consistent in each. These results suggest that new cells are constantly born outside the deprived region of cortex (at least within the primary sensorimotor, prefrontal, and posterior parietal regions), but that precursors in these areas do not differentiate into neurons. It is still possible that future studies will show very low base levels of adult neurogenesis in regions unaffected by injury, such as the prefrontal and posterior parietal cortex, but this was not borne out in our studies at the spatial and temporal resolution examined. It should be noted, however, that the BrdU survival time used in the present study has previously been shown in a positive earlier report of adult cortical neurogenesis (Gould et al., 2001) to be one in which very low numbers are present, which could make detection of BrdU/NeuN-colabeled cells difficult.

Though the behavioral dexterity of the monkeys used in this study was not assessed systematically over the postlesion period, each monkey was still trained and monitored in their performance of a reach-grasp-retrieval task, as has been described in detail in an earlier article (Darian-Smith and Ciferri, 2005). This showed an initial severe deficit of fine motor control in these monkeys, and a subsequent recovery of function in the digits over the weeks and months after the lesion, which is typical with these lesions (Darian-Smith and Ciferri, 2005). It should also be noted that monkeys also underwent daily enrichment in the form of human interaction with the behavioral training, in addition to their standard cage enrichment (which includes a wide-ranging diet, daily videos, music, and novel puzzles and toys). The impact of the hand training on lesion-induced neurogenesis is not known, although environmental enrichment has been shown to increase neurogenesis in the hippocampus (Komitova et al., 2005; Olson et al., 2006).

Together, our findings provide the first demonstration that a cervical dorsal rhizotomy in the nonhuman primate induces cortical neurogenesis within the input-deprived primary somatosensory and motor cortex. Understanding the role of this neurogenesis in the reorganization of the cortical circuitry, and in the subsequent recovery of hand function (e.g., as a replacement or augmentation mechanism) will be important for directing the development of appropriate therapeutic strategies that aim to maximize functional recovery. It will also be important to decipher the environmental conditions that support injury-induced endogenous neurogenesis at multiple levels of the sensorimotor pathway over the long term.

\section{References}

Bareyre FM, Kerschensteiner M, Raineteau O, Mettenleiter TC, Weinmann O, Schwab ME (2004) The injured spinal cord spontaneously forms a new intraspinal circuit in adult rats. Nat Neurosci 7:269-277.

Bauer S, Patterson PH (2005) The cell cycle-apoptosis connection revisited in the adult brain. J Cell Biol 171:641-650.

Bernier PJ, Bedard A, Vinet J, Levesque M, Parent A (2002) Newly generated neurons in the amygdala and adjoining cortex of adult primates. Proc Natl Acad Sci U S A 99:11464-11469. 
Burns KA, Ayoub AE, Breunig JJ, Adhami F, Weng WL, Colbert MC, Rakic P, Kuan CY (2007) Nestin-CreER mice reveal DNA synthesis by nonapoptotic neurons following cerebral ischemia-hypoxia. Cereb Cortex 17: 2585-2592.

Cameron HA, Dayer AG (2008) New interneurons in the adult neocortex: small, sparse, but significant? Biol Psychiatry 63:650-655.

Cameron HA, McKay RD (2001) Adult neurogenesis produces a large pool of new granule cells in the dentate gyrus. J Comp Neurol 435:406-417.

Chi L, Ke Y, Luo C, Li B, Gozal D, Kalyanaraman B, Liu R (2006) Motor neuron degeneration promotes neural progenitor cell proliferation, migration, and neurogenesis in the spinal cords of amyotrophic lateral sclerosis mice. Stem Cells 24:34-43.

Christie BR, Cameron HA (2006) Neurogenesis in the adult hippocampus. Hippocampus 16:199-207.

Danilov AI, Covacu R, Moe MC, Langmoen IA, Johansson CB, Olsson T, Brundin L (2006) Neurogenesis in the adult spinal cord in an experimental model of multiple sclerosis. Eur J Neurosci 23:394-400.

Darian-Smith C, Brown S (2000) Functional changes at periphery and cortex following dorsal root lesions in adult monkeys. Nat Neurosci 3:476-481.

Darian-Smith C, Ciferri M (2006) Cuneate nucleus reorganization following cervical dorsal rhizotomy in the macaque monkey: its role in the recovery of manual dexterity. J Comp Neurol 498:552-565.

Darian-Smith C, Ciferri MM (2005) Loss and recovery of voluntary hand movements in the macaque following a cervical dorsal rhizotomy. J Comp Neurol 491:27-45.

Darian-Smith C, Darian-Smith I (1993) Thalamic projections to areas 3a, $3 \mathrm{~b}$, and 4 in the sensorimotor cortex of the mature and infant macaque monkey. J Comp Neurol 335:173-199.

Darian-Smith C, Tan A, Edwards S (1999) Comparing thalamocortical and corticothalamic microstructure and spatial reciprocity in the macaque ventral posterolateral nucleus (VPLc) and medial pulvinar. J Comp Neurol 410:211-234.

Dayer AG, Cleaver KM, Abouantoun T, Cameron HA (2005) New GABAergic interneurons in the adult neocortex and striatum are generated from different precursors. J Cell Biol 168:415-427.

Evarts EV, Fromm C (1977) Sensory responses in motor cortex neurons during precise motor control. Neurosci Lett 5:267-272.

Feeney C, Stys P (2005) Astrocyte injury. In: Neuroglia (Kettenmann H, Ransom B, eds), pp 421-429. New York: Oxford UP.

Fowler CD, Liu Y, Wang Z (2008) Estrogen and adult neurogenesis in the amygdala and hypothalamus. Brain Res Rev 57:342-351.

Ge S, Sailor KA, Ming GL, Song H (2008) Synaptic integration and plasticity of new neurons in the adult hippocampus. J Physiol 586:3759-3765.

Gould E (2007) How widespread is adult neurogenesis in mammals? Nat Rev Neurosci 8:481-488.

Gould E, Reeves AJ, Graziano MS, Gross CG (1999) Neurogenesis in the neocortex of adult primates. Science 286:548-552.

Gould E, Vail N, Wagers M, Gross CG (2001) Adult-generated hippocampal and neocortical neurons in macaques have a transient existence. Proc Natl Acad Sci U S A 98:10910-10917.

Hou SW, Wang YQ, Xu M, Shen DH, Wang JJ, Huang F, Yu Z, Sun FY (2008) Functional integration of newly generated neurons into striatum after cerebral ischemia in the adult rat brain. Stroke 39:2837-2844.

Imayoshi I, Sakamoto M, Ohtsuka T, Takao K, Miyakawa T, Yamaguchi M, Mori K, Ikeda T, Itohara S, Kageyama R (2008) Roles of continuous neurogenesis in the structural and functional integrity of the adult forebrain. Nat Neurosci 11:1153-1161.

Jessberger S, Parent JM (2008) Epilepsy and adult neurogenesis. In: Adult neurogenesis (Gage FH, Kempermann G, Song H, eds), pp 535-548. New York: Cold Spring Harbor Laboratory.

Jiao J, Chen DF (2008) Induction of neurogenesis in nonconventional neurogenic regions of the adult central nervous system by niche astrocyteproduced signals. Stem Cells 26:1221-1230.

Kaplan MS (1981) Neurogenesis in the 3-month-old rat visual cortex. J Comp Neurol 195:323-338.

Kokaia Z, Thored P, Arvidsson A, Lindvall O (2006) Regulation of strokeinduced neurogenesis in adult brain-recent scientific progress. Cereb Cortex 16:i162-i167.

Koketsu D, Mikami A, Miyamoto Y, Hisatsune T (2003) Nonrenewal of neurons in the cerebral neocortex of adult macaque monkeys. J Neurosci 23:937-942.
Komitova M, Mattsson B, Johansson BB, Eriksson PS (2005) Enriched environment increases neural stem/progenitor cell proliferation and neurogenesis in the subventricular zone of stroke-lesioned adult rats. Stroke 36:1278-1282.

Kornack DR, Rakic P (2001) Cell proliferation without neurogenesis in adult primate neocortex. Science 294:2127-2130.

Leuner B, Kozorovitskiy Y, Gross CG, Gould E (2007) Diminished adult neurogenesis in the marmoset brain precedes old age. Proc Natl Acad Sci U S A 104:17169-17173.

Ling L, Zeng J, Pei Z, Cheung RT, Hou Q, Xing S, Zhang S (2009) Neurogenesis and angiogenesis within the ipsilateral thalamus with secondary damage after focal cortical infarction in hypertensive rats. J Cereb Blood Flow Metab 29:1538-1546.

Liu YP, Lang BT, Baskaya MK, Dempsey RJ, Vemuganti R (2009) The potential of neural stem cells to repair stroke-induced brain damage. Acta Neuropathol 117:469-480.

Lledo PM, Alonso M, Grubb MS (2006) Adult neurogenesis and functional plasticity in neuronal circuits. Nat Rev Neurosci 7:179-193.

Magavi SS, Leavitt BR, Macklis JD (2000) Induction of neurogenesis in the neocortex of adult mice. Nature 405:951-955.

Mitchell BD, Emsley JG, Magavi SS, Arlotta P, Macklis JD (2004) Constitutive and induced neurogenesis in the adult mammalian brain: manipulation of endogenous precursors toward CNS repair. Dev Neurosci 26:101-117.

Olson AK, Eadie BD, Ernst C, Christie BR (2006) Environmental enrichment and voluntary exercise massively increase neurogenesis in the adult hippocampus via dissociable pathways. Hippocampus 16:250-260.

Parent JM (2002) The role of seizure-induced neurogenesis in epileptogenesis and brain repair. Epilepsy Res 50:179-189.

Parent JM, Vexler ZS, Gong C, Derugin N, Ferriero DM (2002) Rat forebrain neurogenesis and striatal neuron replacement after focal stroke. Ann Neurol 52:802-813.

Rausell E, Bickford L, Manger PR, Woods TM, Jones EG (1998) Extensive divergence and convergence in the thalamocortical projection to monkey somatosensory cortex. J Neurosci 18:4216-4232.

Rolls A, Shechter R, Schwartz M (2009) The bright side of the glial scar in CNS repair. Nat Rev Neurosci 10:235-241.

Schofield BR (2008) Retrograde axonal tracing with fluorescent markers. Curr Protoc Neurosci April:chapter 1, unit 1.17.

Scott BW, Wang S, Burnham WM, De Boni U, Wojtowicz JM (1998) Kindling-induced neurogenesis in the dentate gyrus of the rat. Neurosci Lett 248:73-76.

Silver J, Miller JH (2004) Regeneration beyond the glial scar. Nat Rev Neurosci 5:146-156.

Strick PL, Preston JB (1978) Sorting of somatosensory afferent information in primate motor cortex. Brain Res 156:364-368.

Tanji J, Wise SP (1981) Submodality distribution in sensorimotor cortex of the unanesthetized monkey. J Neurophysiol 45:467-481.

Taupin P (2007) BrdU immunohistochemistry for studying adult neurogenesis: paradigms, pitfalls, limitations, and validation. Brain Res Rev 53:198-214.

Thored P, Arvidsson A, Cacci E, Ahlenius H, Kallur T, Darsalia V, Ekdahl CT, Kokaia Z, Lindvall O (2006) Persistent production of neurons from adult brain stem cells during recovery after stroke. Stem Cells 24:739-747.

Vandenbosch R, Borgs L, Beukelaers P, Belachew S, Moonen G, Nguyen L, Malgrange B (2009) Adult neurogenesis and the diseased brain. Curr Med Chem 16:652-666.

Vessal M, Aycock A, Garton MT, Ciferri M, Darian-Smith C (2007) Adult neurogenesis in primate and rodent spinal cord: comparing a cervical dorsal rhizotomy with a dorsal column transection. Eur J Neurosci 26:2777-2794.

West MJ, Slomianka L, Gundersen HJ (1991) Unbiased stereological estimation of the total number of neurons in the subdivisions of the rat hippocampus using the optical fractionator. Anat Rec 231:482-497.

Wu CW, Kaas JH (2003) Somatosensory cortex of prosimian Galagos: physiological recording, cytoarchitecture, and corticocortical connections of anterior parietal cortex and cortex of the lateral sulcus. J Comp Neurol 457:263-292.

Yang H, Lu P, McKay HM, Bernot T, Keirstead H, Steward O, Gage FH, Edgerton VR, Tuszynski MH (2006) Endogenous neurogenesis replaces oligodendrocytes and astrocytes after primate spinal cord injury. J Neurosci 26:2157-2166. 